MISES: Revista Interdisciplinar de Filosofia, Direito e Economia

ISSN 2318-0811

Volume I, Número 1 (Janeiro-Junho 2013): 261-264

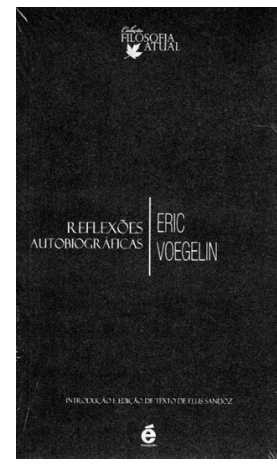

\title{
Reflexões Autobiográficas
}

Eric Voegelin

Introdução e edição de texto por Ellis Sandoz

Notas à edição brasileira de Martim Vasques da Cunha

Tradução de Maria Inês de Carvalho

São Paulo: É Realizações, 2008. (190 páginas)

ISBN: 978-85-88062-50-4

$\mathrm{E}$

ric Voegelin (1901-1985) é um autor pouco discutido no ambiente acadêmico. A leitura de suas Reflexões Autobiográficas deixa evidente que a lacuna não se deve a nenhum demérito do pensador austríaco, mas à ousadia e originalidade do seu pensamento. Ao longo da narrativa, observamos o progressivo desenvolvimento intelectual de um pesquisador que termina por propor uma nova fundação da ciência política - um pensamento tão ambicioso e radicalmente independente requer um tempo considerável para ser digerido.

O livro em questão é um obra tão breve quanto instigante. Sua primeira versão foi engendrada por Ellis Sandoz, aluno de Voegelin, que conduziu uma série de entrevistas com seu orientador para um livro próprio. Posteriormente, em 1989, com revisões e correções do próprio Voegelin, as entrevistas seriam publicadas como obra independente. Os leitores brasileiros tem acesso ao texto por meio de uma cuidadosa edição publicada pela É Realizações. A tradução, realizada por Maria Inês de Carvalho, realiza algo raro em edições acadêmicas: o texto permanece sempre fluido, agradável e, mesmo em seus momentos mais densos, perfeitamente compreensível. As notas críticas, preparadas por Martim Vasques da Cunha, fazem o importante trabalho de indicar os conceitos centrais e recomendar a bibliografia relevante para o aprofundamento da discussão. O livro consiste em 29 curtos capítulos; em geral, cada qual dedicado a um problema teórico ou período específico da vida do autor. $\mathrm{O}$ volume brasileiro traz ainda uma breve e adequada introdução cunhada por Ellis Sandoz. O leitor iniciante sentirá falta apenas de alguma espécie de posfácio que lhe guie em explorações futuras pelo vasto corpus do autor.
A obra possui uma enganadora aparência de simplicidade. Embora os primeiros capítulos pareçam se restringir ao relato de dados biográficos e comentários contextuais, o livro rapidamente ganha fôlego teórico e se converte em um profundo comentário sobre as tradições intelectuais que formaram o século XX. Voegelin começa descrevendo sua formação e prossegue com a narrativa da sua carreira acadêmica; nas entrelinhas, no entanto, há um profundo comentário cultural em construção, culminando na apresentação de uma filosofia original. Essa breve obra termina por cumprir três funções importantes: introduz o leitor ao pensamento de Voegelin, descreve as transformações culturais que formam a teoria política do século XX e apresenta a progressiva evolução interior de um autêntico scholar. Para o nosso país, cuja cultura acadêmica ainda esta em fase de germinação, essa última lição talvez seja a mais importante.

Vale a pena se deter no contexto cultural da formação de Voegelin. Nascido no início do século, sua formação se inicia na Áustria do entre-guerras, um período igualmente marcado pela turbulência política e pela efervescência intelectual. $\mathrm{O}$ autor entra na Universidade de Viena em 1919, tendo a oportunidade de estudar - seja diretamente, seja com discípulos diretos - o pensamento das das grandes mentes do início do século. $\mathrm{O}$ autor cita como influências particularmente marcantes a Teoria Pura do Direito de Hans Kelsen (1881-1973) e a Escola Austríaca de Economia representada, na época, por Friedrich von Wieser (1851-1926) e Ludwig von Mises (1881-1973). O que é notável, no entanto, é a amplitude das influências de Voegelin nessa etapa inicial de sua formação: tendo adquirido uma formação clássica, com amplo domínio 
de diversos idiomas, e tendo desenvolvido um forte interesse literário e matemático ainda no colegial, ele aproveita o período universitário para se alimentar das mais diversas fontes culturais. Voegelin se interessa por Física, História da Arte, Psicologia, Ciência Política e Direito. Essa pluralidade de referências é um indício da obra particularmente abrangente que produziria na maturidade. É interessante observar que, mesmo na presença de uma comunidade acadêmica particularmente erudita, as cátedras universitárias não monopolizavam o debate intelectual da sociedade austríaca. Voegelin relata a participação ativa em seminários e grupos de discussão de membros dos mais variados segmentos da sociedade, incluindo empresários, funcionários públicos e líderes políticos. Essa diversidade garantia uma pluralidade de perspectivas que frequentemente falta aos nossos debates contemporâneos, além de encorajar a discussão direta sem o subterfúgio da utilização de uma linguagem hermética, reservada a uma elite acadêmica.

À julgar pela introdução de Sandoz, alguns estudiosos se incomodaram com os comentários críticos de Voegelin a diversos autores e escolas de pensamento relatados no livro. No entanto, deve se considerar que a natureza breve e ensaística do livro impede que Voegelin apresente uma extensa dissertação sobre cada questão, sendo razoável esperar apenas as linhas gerais do seu pensamento. Além disso, deve-se considerar que seus comentários surgem de uma concepção filosófica bastante específica que Voegelin passará toda sua carreira elaborando. Portanto, é recomendável que o leitor considere essas discussões como breves ensaios a serem aprofundados por leituras posteriores e não como provas finais das posições de Voegelin. Preferível à mera aceitação ou rejeição dos argumentos é procurar compreender os pressupostos implícitos na discussão para adquirir uma melhor compreensão da filosofia que está na base da discussão.

Nesse sentido, seu capítulo sobre Max Weber (1864-1920) é emblemático. Voegelin reconhece sua dívida com a obra de Weber, afirmando que seus livros confirmaram sua "rejeição do marxismo como ideologia indefensável cientificamente" (p. 31) e que Weber foi o primeiro a estimular seu interesse pelos estudos comparados das mais diversas civilizações. Esses dois pontos se revelariam cruciais para o pensamento posterior de Voegelin: o desejo em distinguir a pesquisa científica de distorções ideológicas e o desenvolvimento de uma visão teórica ampla o suficiente para abranger as mais diversas formas de organizações sociais surgidas ao longo da história seriam características marcante do seu pensamento. Não obstante a considerável influência de Weber, Voegelin se afastaria do autor em pontos cruciais. Apesar de reconhecer a importância da distinção entre os valores pessoais do pesquisador e as relações de causa e efeito na sociedade expostas por Weber no célebre ensaio Ciência $e$ Política: Duas Vocações, Voegelin conclui que sua noção de "ética da responsabilidade" é insuficiente. Voegelin critica Weber por deixar de fora do exame científico as experiências que formam os valores do investigador e, portanto, terminam por influenciar a própria atividade científica ao fornecer "os critérios para embasar a ordem existencial e a ação responsável" (p. 32). Evidentemente, esse exame da experiência não seria possível dentro dos limites epistemológicos da época, de modo que essa crítica só pode ser compreendida a partir da refundação da ciência política proposta pelo próprio Voegelin.

Algo análogo ocorre com a crítica voegeliana à Teoria Pura do Direito de Kelsen e à metodologia neokantiana. O retorno ao Immanuel Kant (1724-1804) da segunda metade do século XIX deixara uma marca significativa na cultura acadêmica européia que ainda perdurava na primeira metade do século XX. O neokantismo do período - apesar das diversas variações internas - tem como característica marcante o foco na tentativa de reorganizar o conhecimento em bases epistemológicas firmes que seriam encontradas na obra de Kant. Em linhas gerais, se trata de identificar as categorias puras que delimitam cada domínio do conhecimento para realizar uma análise puramente lógica, descontaminada da interferência arbitrária dos dados empíricos. Voegelin prontamente reconhece que esse esforço analítico gera frutos admiráveis, tendo mesmo escolhido Kelsen como co-orientador de doutorado. No entanto, Voegelin se sente pouco confortável nos limites estreitos do edifício epistemológico neokantiano. Reconhece o mérito da 
Teoria Pura do Direito em examinar um domínio específico da realidade, mas considera que a teoria política não pode ser reduzida ao âmbito jurídico. Nesse sentido, Voegelin começa sua progressiva ampliação do campo de discussão que o levará a expandir as fronteiras da própria teoria política, passando a fundá-la em uma investigação sobre a origem das experiências de ordem e desordem na alma humana.

Outra discussão importante se refere à questão da linguagem. Influenciado por uma série de estudos literários e pela crítica cultural de Karl Kraus (1874-1936), Voegelin constrói uma concepção da linguagem com sérias ramificações em sua própria filosofia. Neste livro, somos apresentados a duas características importantes dessa discussão. Primeiramente, Voegelin afirma que a falsificação da realidade operada pelos ideológos se reflete em uma distorção da própria linguagem, que perde sua capacidade de servir para as pessoas expressarem satisfatoriamente a própria experiência. Além disso, Voegelin enxerga uma linha direta de causa e efeito entre a destruição da linguagem e a desordem na sociedade. $\mathrm{O}$ modo como um povo utiliza o discurso - a linguagem presente tanto em discussões públicas como nas artes - não constituem mero entretenimento, mas causa direta das transformações sociais futuras.

Apesar da notável erudição do ambiente em que se formou, Voegelin relata que suas experiências no exterior foram fundamentais para lhe libertar de seu "provincianismo centro-europeu". Em particular, relata os benefícios advindos de sua experiência nos Estados Unidos. Ele primeiro visitara o país como estudante, depois como acadêmico em fuga do totalistarismo nazista. Meditando sobre as diferenças culturais entre os dois ambientes culturais, Voegelin novamente se depara com a necessidade ir além dos limites epistemológicos que marcaram sua formação anterior. Percebe que, mesmo na ausência de uma cultura erudita tão marcante quanto a austríaca, o cidadão médio norte-americano tem uma atitude pessoal significativamente mais aberta e saudável diante da realidade. Essa observação leva Voegelin a estudar a filosofia do common sense, concluindo que havia uma espécie de bom-senso intrínseco à sociedade norte-ame- ricana que a tornava mais receptível à absorção do legado da filosofia clássica e das tradições religiosas. Esse insight seria fundamental para a virada que Voegelin realizaria posteriormente no campo da teoria política.

A carreira de Voegelin prosperara no novo continente. Leciona em universidades norte-americanas por duas décadas, antes de retornar temporariamente para a Europa, para fundar um Instituto de Ciências Políticas. Voegelin se encontra tão adaptado ao seu país de adoção que sente necessidade de justificar o retorno: interessara-lhe a possibilidade de participar da fundação de uma nova instituição de pesquisa e de orientar alunos que poderiam ter um impacto na cultura européia. Não seria, no entanto, um retorno permanente; voltaria ao Estados Unidos, assumindo uma cátedra na Universidade de Stanford, onde continuaria ensinando e escrevendo pelo resto da vida.

Paradoxalmente, o evento mais notável de sua carreira norte-americana talvez tenha sido um trabalho que não pôde terminar. Incumbido por um editor da McGraw-Hill de elaborar um manual de teoria política, Voegelin se lançou em uma aventura intelectual que, em última instância, lhe levaria a reformular as próprias bases da filosofia política. Como bom acadêmico, iniciou o trabalho fazendo uma revisão da bibliografia existente, chegando à conclusão de que deixava muito a desejar no exame das fontes originais. Começou rastreando o caminho tradicional da evolução do pensamento ocidental, passando da Grécia antiga às fontes medievais ao advento da da modernidade. Nesse trajeto, no entanto, Voegelin percebe que os manuais existentes forneciam uma imagem significativamente distorcida dessa história por não realizarem um exame suficientemente detalhado das fontes originais. Voegelin, então, decide que não poderia cumprir a tarefa prometida por precisar aprofundar enormemente a própria formação antes de realmente compreender os assuntos em discussão. Passaria os anos seguintes progressivamente ampliando o escopo da sua investigação - estudando hebraico para compreender as fontes cristãs do pensamento medieval, chinês para compreender o pensamento de Confúcio e Lao-Tsé, e infindáveis linhas de investigação paralelas - procuran- 
do adquirir uma visão de conjunto sobre o modo como diferentes culturais engendram diferentes instituições políticas.

Embora a amplitude desses estudos seja assombroso para os padrões comuns, a erudição de Voegelin não seria o aspecto mais notável do seu projeto. Ao longo dessa investigação, ele teria um insight fundamental que o levaria a reformular a própria metodologia dentro da qual vinha operando. Voegelin conclui que a noção de uma história das ideias é intrinsecamente falsa, pois as ideias não correspondem às forças motrizes efetivas nos processos de transformações sociais. Voegelin observa que a noção mesma de "ideia" não é uma característica essencial das civilizações e empreendimentos teóricos por ele estudados. Observa que estava ausente dos princípios da filosofia clássica, surgindo como um conceito particular dos estóicos, para designar um puro objeto mental. Voegelin terminará por concluir que utilizamos o termo para designar derivações mentais de estruturais mais primitivas dos processos de subjetivação humana. $\mathrm{O}$ chamado "debate de ideias" seria apenas uma elaboração a posteriori dos símbolos produzidos por uma cultura para representar sua experiência da realidade. Seguindo essa linha de raciocínio, Voegelin transformará radicalmente o sentido da teoria política. Se as ideias não são importantes em si mesmas, o verdadeiro objeto da teoria política deve ser o estudo de como esses símbolos surgem e se convertem em instituições sociais. Portanto, ao invés de discutir os diferentes tipos de construções intelectuais criadas em defesa de determinadas ordens políticas, passa a investigar os processos básicos de simbolização da experiência humana que dão origem às ordens sociais.

O livro ainda traz, em seus capítulos finais, uma breve descrições dos pontos centrais da filosofia voegeliana. Livre das amarras neokantianas, precisa desenvolver uma nova metodologia e um novo vocabulário técnico para lidar com os problemas que ele mesmo levantou. Tomará de romancistas austríacos a expressão "segunda realidade" para se referir às falsas imagens da realidade criadas pelos ideólogos em estado de alienação. Ele colocará como novo objetivo da filosofia política a tarefa de reconstruir o modo como adquirimos consciência da nossa experiência da realidade. Ele também emprestará o termo anamnese da filosofia clássica para se referir ao processo pelo qual o pesquisador, por meio de um auto-exame das experiências que formaram a própria consciência, retoma contato com sua experiência da realidade.

Nesse ponto, podemos compreender a dificuldade da academia em digerir o pensamento de Voegelin: suas obras de maturidade relegam as principais discussões acadêmicas para segundo plano, propondo uma refundação da ciência política. Não se trata meramente de uma discordância em relação às conclusões finais, mas em uma tentativa em reconstruir o conhecimento da área em novas bases. Evidentemente, um projeto tão ambicioso não pode ser exaustivamente descrito em poucas páginas. Em linhas gerais, no entanto, podemos afirmar que Voegelin propõe uma nova linha de investigação onde a filosofia e a ciência política se revelam como atividades inseparáveis: o auto-exame filosófico é a primeira etapa para esclarecer nossa experiência da estrutura da realidade e o estudo científico dos símbolos políticos é necessário para esclarecer como as tradições culturais moldam nossa experiência do mundo. Em suma: as pesquisas de Voegelin o levam a elaborar uma filosofia original e lançar novas bases para a ciência política. Nesse sentido, Reflexões Autobiográficas é um livro extremamente recomendável a qualquer leitor com inclinações filosóficas interessado em mergulhar em uma investigação sobre os fundamentos da teoria política.cos

Lucas Mafaldo Oliveira

Mestre e doutorando em Filosofia pela Universidade Federal do Rio Grande do Norte (UFRN) Bolsista da Coordenação de Aperfeiçoamento de Pessoal de Nível Superior (CAPES) Bacharel em Psicologia pela UFRN lucasmafaldo@hotmail.com 